\title{
Pharmacy and Therapeutics Committees: Leadership Opportunities in Medication Safety for Medical Toxicologists
}

\author{
Jeanmarie Perrone • Lewis S. Nelson
}

Published online: 26 March 2011

(C) American College of Medical Toxicology 2011

Few residencies or fellowships provide preparation for the many committee responsibilities facing clinicians in an academic or community hospital. This is unfortunate as these assignments are often rich with educational experiences for trainees and young faculty. Although committee work can be time consuming, some of these hospital committees can be very influential in critical decisions about hospital philosophy. Many of these committees are mandatory infrastructural requirements for hospital accreditation by the Joint Commission, and the medical center leadership can view participation favorably. One committee that integrates squarely into the specialty of medical toxicology is the Pharmacy and Therapeutics (P\&T) committee, sometimes aptly named the Formulary Committee. Charged with determining the hospital formulary, decisions are made about the inclusion or exclusion of new pharmacotherapeutic and diagnostic agents for inpatients and outpatients. This committee is typically composed of a multidisciplinary team of pharmacy, physician, nursing, and hospital clinical and administrative leadership.

As the tasks and responsibilities of the Pharmacy and Therapeutics committee evolve and increase, more opportunities are created for individual involvement $[1,2]$. A survey of the ACMT membership in 2007 revealed that

J. Perrone $(\bowtie)$

Division of Medical Toxicology,

Department of Emergency Medicine, University of Pennsylvania,

Philadelphia, PA, USA

e-mail: perronej@uphs.upenn.edu

L. S. Nelson

Medical Toxicology, Bellevue Hospital,

New York City Poison Center, New York University,

455 1st Avenue,

New York, NY 10016, USA

e-mail: lewis.nelson@nyumc.org
$46 \%$ of its medical toxicologists participated in their P\&T committee and $14 \%$ were chair [ACMT Unpublished data]. In our experience, the unique and relevant perspective of a medical toxicologist has proven to be a welcome, mutually beneficial addition to this committee.

\section{History and Current Role of Pharmacy and Therapeutics Committees}

Formularies have been used by a wide spectrum of organizations in the USA for the past several hundred years, starting with the Revolutionary army and progressing to our current Veteran's Affairs National Formulary. The first published formulary system in a US hospital was described in a book review in JAMA in 1949, entitled Formulary, Bellevue Hospital. The author referred to the use of a formulary committee to aid drug selection: "the purpose of the formulary is 'first, to assure that the patients treated at Bellevue Hospital are given the benefit of the most effective and accepted therapy; second, the institution, because of its vast teaching facilities, has the obligation to the physician to have available to him the most recent advances in therapy.' The formulary is not a textbook of therapeutics or pharmacology, and provides no indication of the therapeutic use of the contained drugs. This is the way hospital formularies should be prepared, and the committee is right in feeling 'strongly that no one should use a drug until he is thoroughly familiar with its pharmacologic action, therapeutic indications, dosage, and signs of toxicity [3]."”

Although other countries with a national medical system create a "National Formulary" for practical reasons, the initial focus of early hospital-based Pharmacy and Therapeutics committees was to outline a rational approach to 
medication use. In 1965, the Joint Commission on Accreditation of Hospitals (now the Joint Commission) mandated that hospitals have a P\&T committee. As pharmacotherapeutics advanced, the P\&T committee became charged with assessing additional and increasingly complex drugs for safety, efficacy, and cost [4]. Restricting the formulary helps clinicians by recommending particular medications on a hospital formulary, and streamlines pharmacy administration, controls expenses, and creates opportunities to limit errors by narrowing the spectrum of available medications. The potential to apply best-practices and evidence-based medicine, if done using an intellectually rigorous approach, should improve patient outcome and satisfaction while controlling cost and risk, the ultimate goals of the modern healthcare system.

\section{Additional Pharmacy and Therapeutics Committee Functions and Challenges}

Since approval by the FDA does not necessarily imply a therapeutic or safety advantage over existing therapy, an independent assessment of the safety and possible benefit of the drug (over existing drugs) must be performed. While new drugs are scrutinized with the intent of making decisions about formulary additions, this committee (or one of its collaborating committees or subcommittees, such as Medication Safety or Adverse Drug Effects) is also charged with reviewing emerging safety data, FDA mandated boxed warnings, and postmarketing surveillance toxicity data to determine when a drug should no longer be used (formulary deletions) or used in limited settings in the hospital (restricted use) [5]. Increasingly, the P\&T committee may be asked to investigate an adverse drug event or perform a root cause analysis following a medication error or serious adverse event. The goal of this process is to devise methods for improving the drug utilization processes in the hospital. Furthermore, implementation and monitoring of the Joint Commission's Core Measures and National Patient Safety Goals, such as glycemic control, anticoagulation therapy monitoring, and medication reconciliation has in many institutions been relegated to P\&T or one of its subcommittees [6].

The Pharmacy and Therapeutics committee may be involved in the drafting and review of policies and clinical guidelines created to improve the safety of other medications used within the hospital. High-risk drugs such as opioids and benzodiazepines have been associated with numerous in-hospital complications and many centers have developed guidelines for their use. These guidelines may be broadly applicable, or highly prescriptive and specify use based on, for example, dose, age, setting, or disease process. For example, the management of ethanol withdrawal in various settings in the hospital (e.g., emergency department (ED), medical or surgical floor, ICU) requires different parameters for monitoring and benzodiazepine dosing.

A related challenge faced by P\&T committees is the use of medications outside of their approved indications [5]. This so called "off label" prescribing is widely practiced and the data viewed by a P\&T committee upon considering a new drug for formulary addition generally lacks off label use information. In pediatric pharmacotherapy this is particularly important given the persistent lack of appropriate age-based data for the vast majority of medications that are administered to children [7,8].

Additionally, issues such as "use of own medications" or "use of alternative therapies" is increasingly common during inpatient hospitalizations, and the committee must work to develop appropriate policies to prevent errors in this process while addressing the liability concerns of hospital administration and legal departments. Also, the attempt by FDA to improve the safety of certain medications through the use of Risk Evaluation and Mitigation Strategies (REMS) has expanded the regulatory role for the P\&T committee $[9,10]$. Although many of these apply to individual prescribers and patients in unique situations, certain REMS require the participation of the medical center in validating credentials and practices.

A recent development, now increasingly faced by $\mathrm{P} \& \mathrm{~T}$ committees, is how to respond to drug shortages. As raw product and production processes are limiting some drug manufacturing, sudden drug shortages occur causing a rapid search for reasonable and safe interim alternatives. Given a broad sense of clinical pharmacology, medical toxicologists can participate in these discussions along with appropriate stakeholders, and guide the committee in choosing an appropriate replacement. Simultaneously, guidelines must be designed to ensure optimal utilization of the remaining stock. The recent shortage of succinylcholine caused internal strife within hospitals over limited supply, and required prompt action by the pharmacy and P\&T committee members to identify comparable alternatives for the various clinical settings in which it is utilized.

The increasing number of "me too" drugs (within a prescribing class) approved by the FDA adds to the difficulty in choosing the safest, most effective, and least costly drug while allowing for some physician autonomy in prescribing [11]. Subtle changes in the relative effects of these new drugs may be touted as consequential, often (almost always) without the benefit of head-to-head comparisons with similar drugs. Fortunately, the current administration has committed to funding comparative effectiveness research that should provide more objective data for formulary choices [12]. 


\section{Conflict of Interest Issues}

A critical issue in medicine, nationally and affecting formulary policy, is the pharmaceutical industry influence on practitioners [13]. A team of specialists, for example, may be persuaded to use a new drug that has been newly marketed and detailed to them either locally or nationally at a professional meeting. A specialist may approach the P\&T committee with a request to add the new drug to the formulary for their use. Unfortunately, one of the major difficulties with the committee process is that conflict of interest can be pervasive yet insidious and alter the outcome of the review. But how well has the possibility of conflict of interest, however subtle, been vetted and addressed? Many P\&T committees have limited screening or do not adequately enforce existing policies [14]. This is complicated by the inherent belief by some that physicians are not subject to such influence [15]. The specialist may, in fact, be viewed as the person with the greatest insight into the clinical utility of the new drug lulling the committee to overlook the influence that industry marketing may bear [16].

\section{Role of the Medical Toxicologist on the P\&T Committee}

For those engaged in the practice of medication safety, such as medical toxicologists, this should be recognized as a prime opportunity to guide our hospital community and colleagues. The medical toxicologists' clinical background and unique knowledge base regarding mechanisms of toxicity and potential medication pitfalls often proves essential to the drug evaluation and review process. As either a committee member or its chair, the medical toxicologist can create a niche of pharmacovigilance by integrating the perspectives of the various stakeholders involved in medication use and safety.

Since the potential for misuse and harm from off label use of medications is great, having committee members with appropriate expertise involved in the decision is critical. Similarly, the unique viewpoint of a medical toxicologist, particularly those who are pediatric trained, can provide relevant insight into safe medication use in this vulnerable population. Furthermore, medical toxicologists can be helpful in collaborating with pharmacy colleagues and administration in promoting the role of specialty clinical pharmacists. This group is shown to improve pharmacotherapy and safe medication use in the clinical setting, such as in the $\mathrm{ED}$, where the rapid pace and intensity of patient care adds risk [17].

We should remain on the forefront of advocating for ethical and conflict free decision-making regarding formu- lary additions. In most cases, due to our broad, clinical focus, medical toxicologists offer an unbiased physician perspective without the ambiguity that a subtle conflict may engender. Conflict of interest disclosures should be addressed at every meeting and annually. We favor an approach where the committee reviews drugs prior to physician request (e.g., shortly after FDA approval) so that the committee is able to examine the data objectively without departmental pressure. We advocate the use of a university- or institution-based public website for Conflict of Interest disclosures, which should be reviewed prior to discussion of any proposals for drug requests to the committee. At the minimum, all participants in the discussion and decision-making process should openly acknowledge their potential conflicts to the entire group. Those with potential conflict should recuse themselves from anything but objective discussion; they should not vote.

We recommend that all academic medical toxicologists or groups offer participation as representatives to their Pharmacy and Therapeutics committee to highlight our position in the emerging role of drug safety advocates. Additionally, when available, medical toxicology fellowship curriculum should include a role for fellows to participate as a guest or as a housestaff representative to their Pharmacy and Therapeutics and related committees.

The experience gained will be an invaluable asset to future medication safety leadership. Forging these collaborations will escalate the role of medical toxicologists in establishing and implementing system-wide medication safety initiatives.

\section{References}

1. American Society of Health System Pharmacists (2008) ASHP guidelines on the pharmacy and therapeutics committee and the formulary system. Am J Health Syst Pharm 65:1272-1283

2. Mittman N, Knowles S (2009) A survey of pharmacy and therapeutic committees across Canada: scope and responsibilities. Can J Clin Pharmacol 16:e171-e177

3. Bernecker EL (1949) Formulary Bellevue hospital. JAMA $140: 258$

4. Hughes D, Reynolds DJ (2009) Pharmacoeconomics: principles and relevance to the activities of drug and therapeutics committees. Clin Med 9(5):490-492

5. Raber JH (2010) The formulary process from a risk management perspective. Pharmacotherapy 30(6 Pt 2):42S-47S

6. Joint commission. National Patient Safety Goals. http://www. jointcommission.org/standards_information/npsgs.aspx. Accessed February 12, 2011

7. Benjamin DK Jr, Smith PB, Murphy MD et al (2006) Peerreviewed publication of clinical trials completed for pediatric exclusivity. JAMA 296(10):1266-1273 
8. Wertheimer A (2011) Off-label prescribing of drugs for children. Curr Drug Saf 6(1):46-48

9. Food and Drug Administration: www.fda.gov/Drugs/DrugSafety/ PostmarketDrugSafetyInformationforPatientsandProviders/ ucm111350.htm. Accessed Feb 12, 2011

10. Wright C 4th, Schnoll S, Bernstein D (2008) Risk evaluation and mitigation strategies for drugs with abuse liability: public interest, special interest, conflicts of interest, and the industry perspective. Ann NY Acad Sci 1141:284-303

11. Gagne JJ, Choudhry NK (2011) How many "Me-Too" drugs is too many? JAMA 305:711-712

12. Ventola CL (2009) President Obama's health care reform policies: Issues of interest to P\& T committees. PT 34(6):296-308

13. Lurie P, Almeida CM, Stine N, Stine AR, Wolfe SM (2006) Financial conflict of interest disclosure and voting patterns at Food and Drug Administration Drug Advisory Committee meetings. JAMA 295(16):1921-1928

14. Farmer BM, Nelson LS (2011) Conflicts of Interest on Pharmacy and Therapeutics Committees at Academic Medical Centers. J Med Toxicol (this is a paper accepted for the same issue of JMT)

15. Cain DM, Detsky AS (2008) Everyone's a little bit biased, even physicians. JAMA 299:2893-2895

16. Silverman GK, Loewenstein GF, Anderson BL, Ubel PA, Zinberg S, Schulkin J (2010) Failure to discount for conflict of interest when evaluating medical literature: a randomised trial of physicians. J Med Ethics 36(5):265-270

17. Rothschild JM, Churchill W, Erickson A et al (2010) Medication errors recovered by emergency department pharmacists. Ann Emerg Med 55(6):513-521 